\title{
Study of Michael-Michael-retro Michael Addition Catalyzed by 9-Amino-9-Deoxyepiquinine Using ESI-MS
}

\author{
Zhi-Jun Wu, ${ }^{a}$ Shi-Wei Luo, ${ }^{\mathrm{b}}$ Jian-Wu Xie, ${ }^{\mathrm{c}}$ Xiao-Ying Xu, ${ }^{\mathrm{c}}$ \\ Dong-Mei Fang, ${ }^{a}$ and Guo-Lin Zhang ${ }^{\mathrm{a}}$ \\ ${ }^{a}$ Chengdu Institute of Biology, Chinese Academy of Sciences, Chengdu, China \\ ${ }^{\mathrm{b}}$ Department of Chemistry, University of Science and Technology of China, Hefei, China \\ ${ }^{\mathrm{c}}$ Key Laboratory of Asymmetric Synthesis and Chirotechnology of Sichuan Province and Union Laboratory \\ of Asymmetric Synthesis, Chengdu Institute of Organic Chemistry, Chinese Academy of Sciences, Chengdu, \\ China
}

The Michael-Michael-retro Michael addition catalyzed by 9-amino-9-deoxyepiquinine was monitored and the major intermediates and catalyst in the catalytic cycle were detected and characterized using ESI-MS/MS for the first time. Some important isomeric intermediates including isomeric enamine and imine structures were tentatively differentiated and further studied by theoretical calculations. Fragment ions of protonated catalyst indicate that proton possibly influences the conformation of the catalyst. (J Am Soc Mass Spectrom 2007, 18, 2074-2080) @ 2007 American Society for Mass Spectrometry

$\mathrm{R}$ ecently, cinchona alkaloids and their derivatives have played a major role in the active field of small-molecule organocatalysts [1]. Many reactions catalyzed by them yield highly enantioselective products. To understand the reaction mechanisms, some studies on the conformation of cinchona alkaloids in the presence of acid were carried out using nuclear magnetic resonance (NMR) spectroscopy [2]. Obviously, studying the catalytic processes and their reaction mechanisms and, if possible, further understanding the structural characteristics of protonated cinchona alkaloids and their derivatives using other methods remains desirable.

Mass spectrometry (MS) has greatly benefited from the development of electrospray ionization (ESI) [3]. ESI is a powerful ion formation technique and it can directly transfer both positive and negative ions from solution to the gas phase [4]. Due to these distinctive characteristics, ESI-MS and its tandem version ESI-MS/MS have rapidly become suitable tools for detection and characterization of reaction intermediates in solution, which can provide direct evidence for mechanistic studies [5-7].

Recently, Chen et al. reported the Michael-Michaelretro Michael addition reactions of $\alpha, \alpha$-dicyanoolefins with $\alpha, \beta$-unsaturated ketones catalyzed by 9 -amino-9deoxyepiquinine, as outlined in Scheme 1. This type of reactions can provide the enantiopure 2-cyclohexen-1-one derivatives [8]. According to Scheme 1, $\alpha, \beta$-unsaturated ketone 2 is activated by the primary amine, which

Address reprint requests to Dr. Z.-J. Wu, Chengdu Institute of Biology, Chinese Academy of Sciences, Chengdu 610041, China. E-mail: wuzhijunyinger@163.com generates iminium intermediate 3 . Intermediate 3 adds to deprotonated acyclic $\beta$-phenyl $\alpha, \alpha$-dicyanoolefins 4 by a Michael addition reaction to yield intermediate $\boldsymbol{6}$. Intermediate 7 is formed by an intramolecular prototrophic shift from 6 , and then intermediate 8 is generated by intramolecular Michael addition. Intermediate 8 produces intermediate $\mathbf{9}$, which further generates the product $\mathbf{1 0}$ and catalyst $\mathbf{1}$ by hydrolysis. To our knowledge, the reaction mechanisms have not yet been investigated. In view of the importance of the reactive utility and the catalyst, in this paper we will attempt to probe the reaction intermediates 3, 5, 6, 8, and 9 (Scheme 1) and understand the structural characteristics of the protonated catalyst using ESI-MS/MS technique and ab initio quantum mechanical calculation.

\section{Experimental}

High-resolution experiments were performed on a Bruker BioTOF-Q mass spectrometer (Billerica, MA) in the positive and negative modes. Accurate masses of fragment ions were determined by external mass calibration using the mass calibrants of MW 622.0290 and 922.0098. High-purity nitrogen gas was used as collision, nebulizer, and auxiliary heated gas at a pressure of 30 psi. The samples introduction rate was $115 \mu \mathrm{L} / \mathrm{h}$. The ESI source conditions in the positive and negative modes were as follows: capillary $\mathrm{V},-4500 \mathrm{~V}$ (positive), $4000 \mathrm{~V}$ (negative); end plate voltage, $-4000 \mathrm{~V}$ (positive), $3500 \mathrm{~V}$ (negative); capillary exit voltage, $100 \mathrm{~V}$; dry gas temperature, $150^{\circ} \mathrm{C}$. Collision energy was optimized according to the signal. 


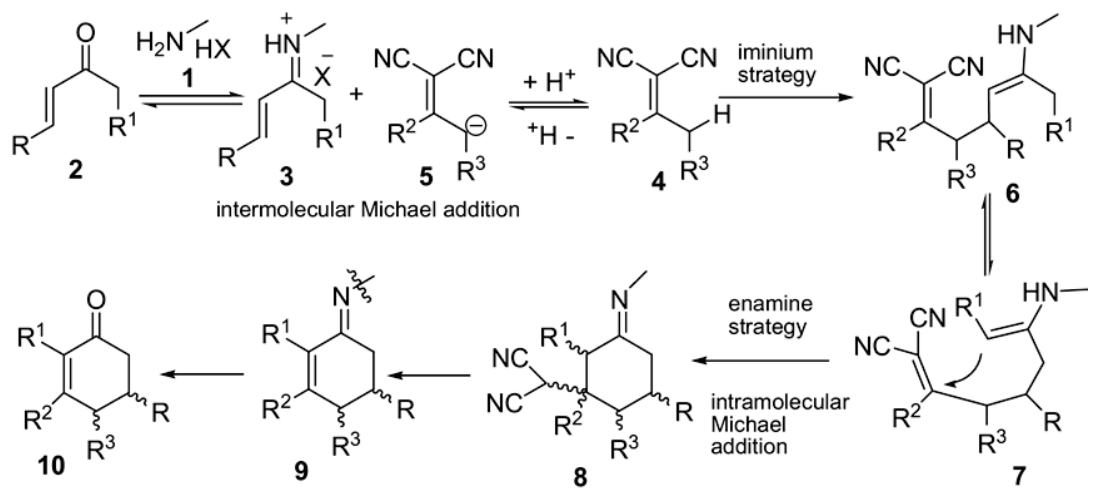

Scheme 1. Proposed Michael-Michael-retro Michael addition reactions based on iminium-enamine activation.

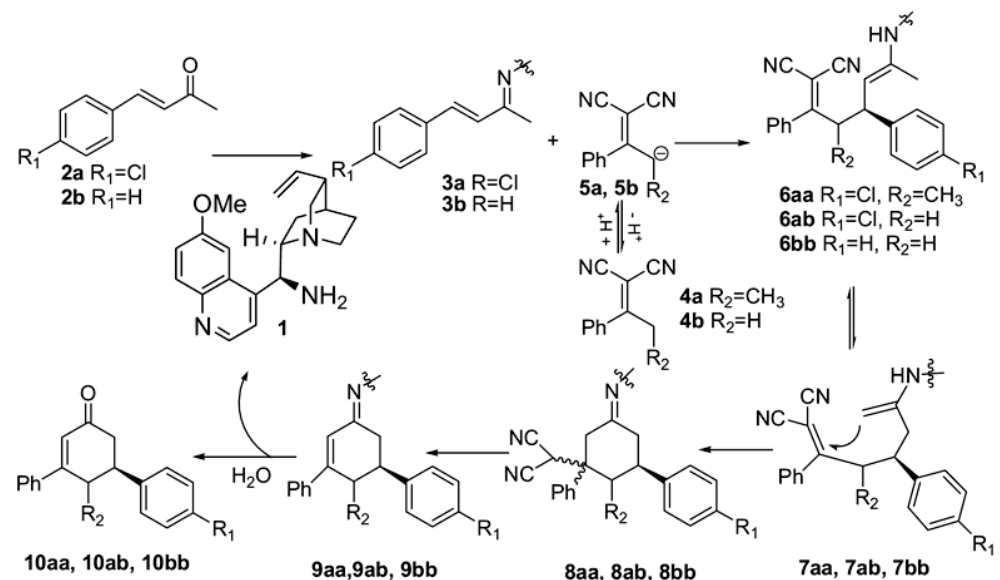

Scheme 2. Michael-Michael-retro Michael addition reactions of $\alpha, \beta$-unsaturated ketones and acyclic $\beta$-phenyl $\alpha, \alpha$-dicyano-olefins catalyzed by 9 -amino-9-deoxyepiquinine. The protonated or deprotonated species are intercepted and structurally characterized by ESI-MS/MS.

Three reaction systems were selected (Scheme 2) and monitored off-line at different intervals (the first day every $2 \mathrm{~h}$ and then a sample every $24 \mathrm{~h}$ up to $216 \mathrm{~h}$ ) using ESI-QTOF. A solution of catalyst (1 $0.002 \mathrm{mmol})$, $\alpha, \beta$-unsaturated ketone ( $2 \mathbf{a}$ or $\mathbf{2 b} 0.01 \mathrm{mmol}$ ), acyclic $\beta$-phenyl $\alpha$, $\alpha$-dicyanoolefin (4a or $4 \mathbf{b} 0.01 \mathrm{mmol}$ ), and TFA $(0.004 \mathrm{mmol})$ in THF $(2 \mathrm{~mL})$ was stirred at room temperature. The mixed sample was diluted by $\mathrm{CH}_{3} \mathrm{OH}$ (1:50) before transfer into the ESI source.

$A b$ initio quantum mechanical calculations were per-

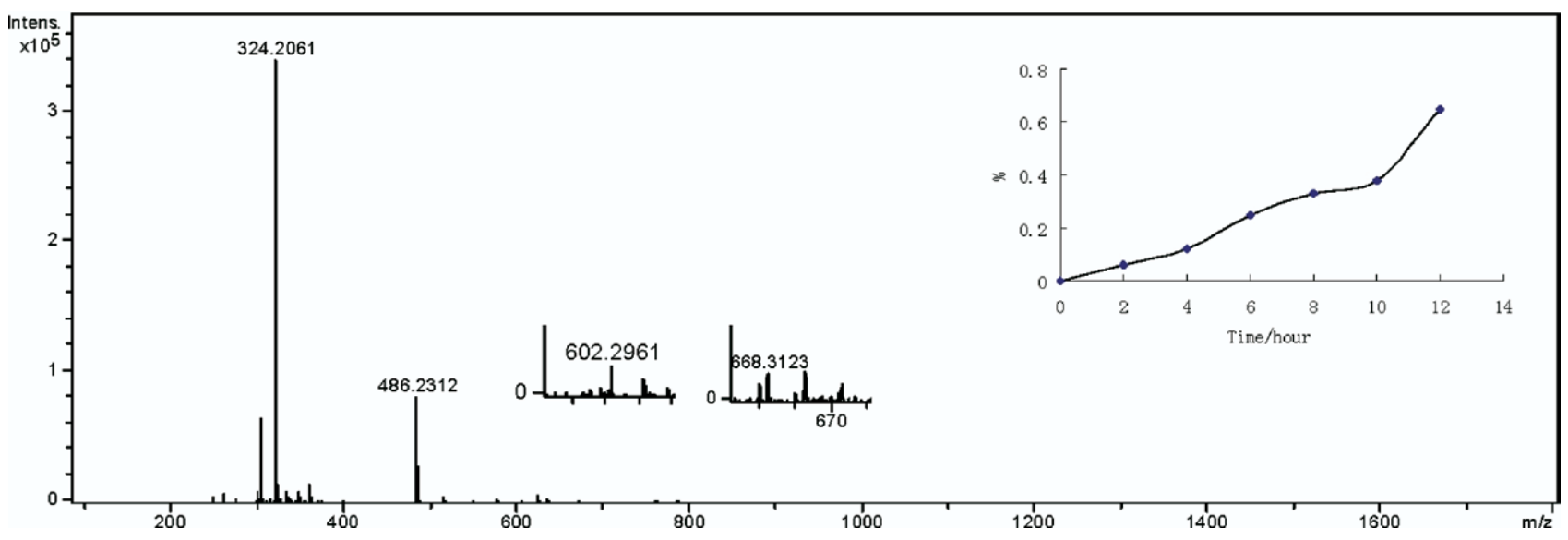

Figure 1. ESI-MS spectrum of the reaction solution of of $\alpha, \alpha$-unsaturated ketone 3 a and acyclic $\beta$-phenyl $\alpha, \alpha$-dicyanoolefin 4 a catalyzed by 9 -amino-9-deoxyepiquinine at $2 \mathrm{~h}$. Time dependence of the ration between 9aa $\cdot \mathrm{H}^{+}\left(\mathrm{m} / \mathrm{z}\right.$ 602) and $\mathbf{1} \cdot \mathbf{H}^{+}(\mathrm{m} / \mathrm{z} 324)$ is shown in the insert. 


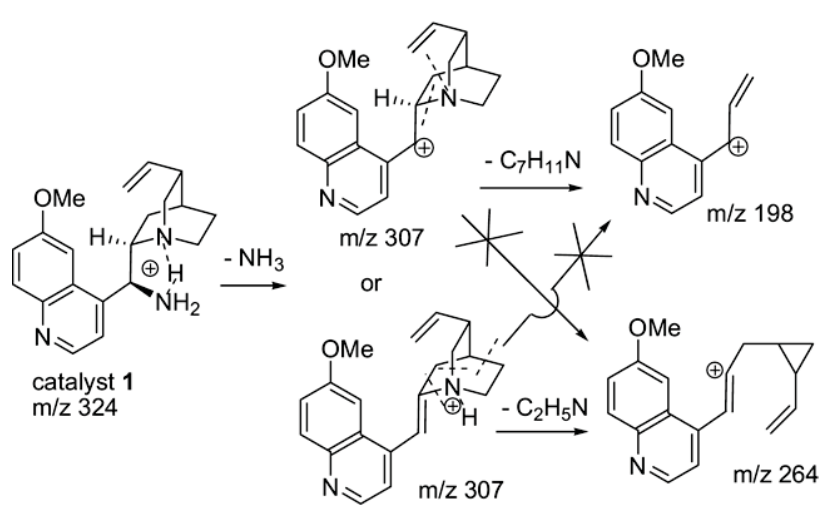

Scheme 3. Possible structures of protonated catalyst and fragment ion at $m / z 307$.

formed with the DFT variant hybrid density functional theory (B3LYP) [9] in conjunction with 6-31G(d) basis set [10] as implemented in the Gaussian 03 program package [11]. The geometries of stationary points and first-order saddle point were identified by frequency analysis, and transition-state (TS) structure was vali-

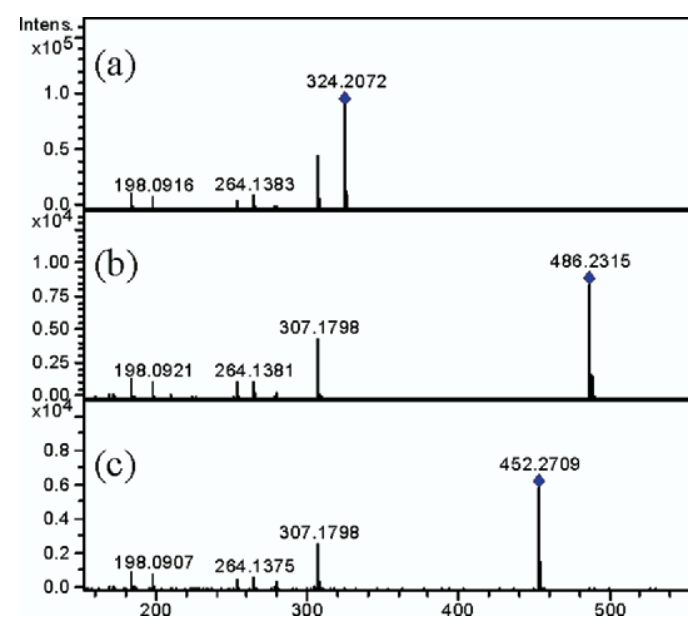

Figure 2. MS/MS spectra of the selected $[\mathrm{M}+\mathrm{H}]^{+}$ions: (a) catalyst 1 (collision energy at $12 \mathrm{eV}),(\mathbf{b})$ intermediate $3 \mathbf{a}$ (collision energy at $20 \mathrm{eV}$ ), (c) intermediate $3 \mathbf{b}$ (collision energy at $20 \mathrm{eV}$ ).

dated with one and only one imaginary frequency related to the forming $\mathrm{C}-\mathrm{C}$ bond. The energy of each structure was evaluated and corrected by calculated

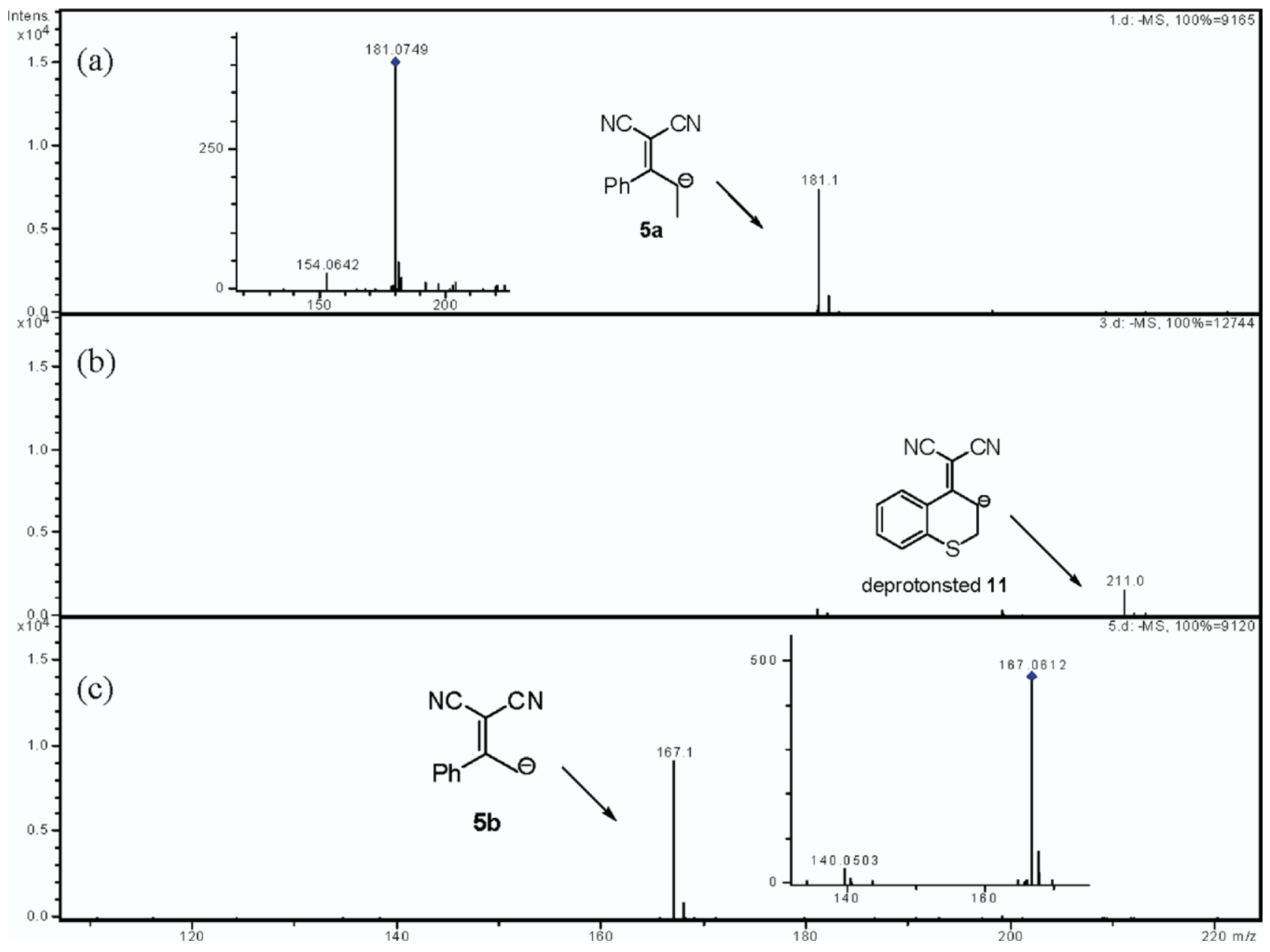

Figure 3. ESI-MS spectra of the $[-\mathrm{H}]^{-}$ions: (a) $4 \mathbf{a}$; (b) 11; (c) $4 \mathbf{b}$. Shown in the insert are MS/MS spectra: (a) the selected intermediate $\mathbf{5 a}$ at $\mathrm{m} / \mathrm{z} 181$ (collision energy at $17 \mathrm{eV}$ ), (c) the selected intermediate $5 \mathbf{b}$ at $\mathrm{m} / \mathrm{z} 167$ (collision energy at $21 \mathrm{eV}$ ). 
<smiles>C=CC1CC2CC1N(C(C)(C)C)[C@H](N)[C@H]2c1ccnc2ccc(OC)cc12</smiles>

$\mathrm{m} / \mathrm{z} 324$<smiles>C=CC1C2CCN1C(CI)C2[C@H](NC(C)(C)C)c1ccnc2ccc(OC)cc12</smiles>

3a, $\mathrm{m} / \mathrm{z} 486$<smiles>C=CC1CC2CCN1C2[C@H](O)c1ccnc2ccc(OC)cc12</smiles><smiles>C=CC(=Cc1ccnc2ccc(OC)cc12)N1C2CCC1C(C=C)C2</smiles>

$\mathrm{m} / \mathrm{z} 307$

(b)

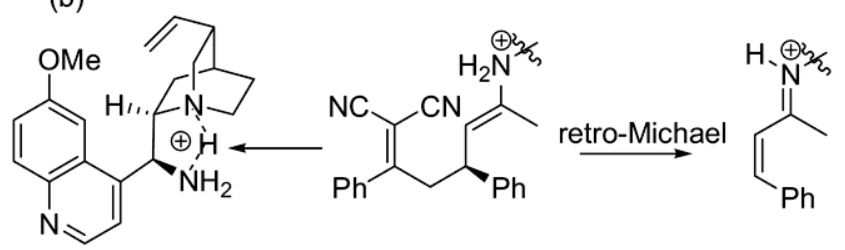
$\mathrm{m} / \mathrm{z} 324$

6aa, m/z 668

$\mathrm{m} / \mathrm{z} 486$

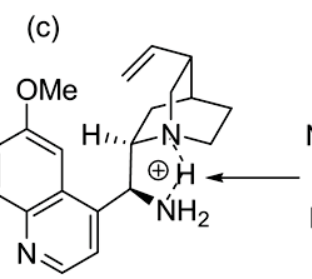<smiles>C=C(N[14C](=O)c1ccccc1)[C@H](CC(=C(C)C#N)c1ccccc1)C(C)(C)C(C)(C)C</smiles>

$\mathrm{m} / \mathrm{z} 324$

(d)<smiles>[R2]C1C(c2ccccc2)=CC(=[Nb])C[C@H]1[PH2+]</smiles>

7aa, m/z 668 $\mathrm{m} / \mathrm{z} 486$<smiles>C=C(N)[C@H](CC([Pb])=C(C#N)C#N)c1ccccc1</smiles>

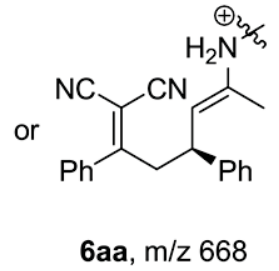

(e)<smiles>[R2]C1C(c2ccccc2)=CC(=[N+]=[N-])C[C@H]1c1ccccc1</smiles>

$\mathrm{m} / \mathrm{z} 602$<smiles>[R2]C1C([PH2+])CC(=[18O])CC1(C(C)(C)C)C(C#N)(C#N)c1ccccc1</smiles>

8aa, m/z 668<smiles>CC(/C=C\c1ccccc1)=[N+]=[NH2+]</smiles>

$\mathrm{m} / \mathrm{z} 486$

Scheme 4. (a) and (b) or (c) indicate that cleavage is difficult to occur on iminium double-bond; (b) and (c) indicate that retro-Michael addition reaction might occur in intermediate 6aa not for 7aa; (d) and (e) indicate that the loss of a $\mathrm{H}_{2} \mathrm{C}(\mathrm{CN})_{2}$ molecule occurs readily in intermediate 8aa.

zero-point energies and thermal effects from the frequency analysis using the B3LYP/6-31G(d) method.

\section{Results and Discussion}

Because of the high sensitivity of ESI-QTOF, the intermediates can be detected even though the concentration is low. However, some unexpected peaks in the low mass region, possibly resulting from the solvent, are also observed due to the high sensitivity. Fortunately, the high-resolution QTOF can distinguish the intermediates from the unexpected peaks unambiguously. The reaction system with mixed catalyst $\mathbf{1}, \mathbf{2} \mathbf{a}, \mathbf{4 a}$, and TFA in THF was studied first. Shortly after $1 \mathrm{~min}$ of reaction, the mixed sample was transferred into the MS and the protonated intermediate $\mathbf{3 a},[3 \mathbf{a}+\mathrm{H}]^{+}(\mathrm{m} / \mathrm{z}$ 486.2295, calcd.: $m / z$ 486.2307), and catalyst $\mathbf{1},[\mathbf{1}+\mathrm{H}]^{+}(m / z$ 324.2081, calcd.: $m / z$ 324.2070), were observed in positive ion mode as major ions (Figure 1). In the negative ion mode, the intermediate [5a] $]^{-}(\mathrm{m} / \mathrm{z}$ 181.0749, calcd.: $\mathrm{m} / \mathrm{z}$ 181.0760, Figure 3) was observed. At 2 h, the signal of 668.3123 corresponding to the protonated intermediate 6aa, 7aa, or 8aa (calcd.: $\mathrm{m} / \mathrm{z}$ 668.3151) was observed although the relative abundance was low (Figure 1). In addition, the observed signal of 602.2961 possibly corresponds to protonated intermediate 9aa (calcd.: $\mathrm{m} / \mathrm{z}$ 602.2933) formed by the loss of a $\mathrm{H}_{2} \mathrm{C}(\mathrm{CN})_{2}$ molecule from intermediate 8aa. The time dependence of the ratio 


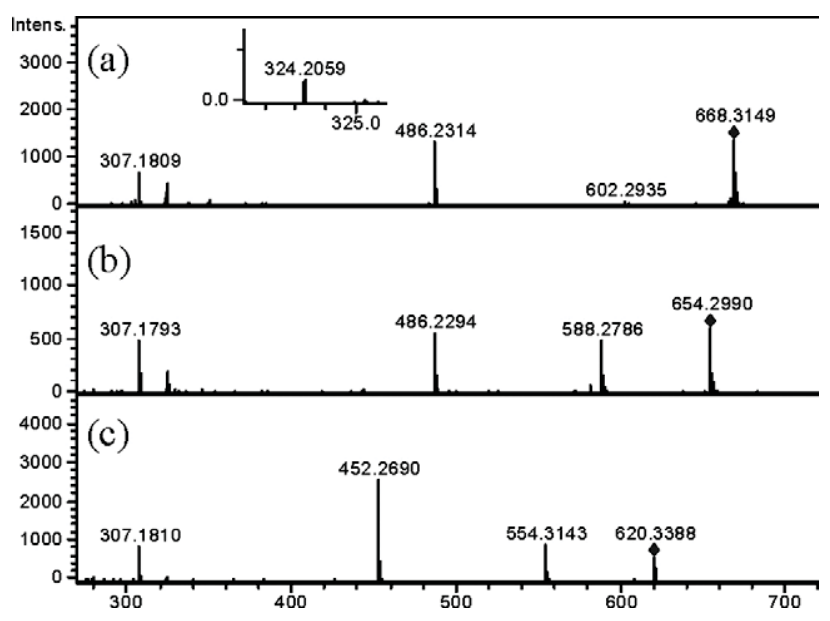

Figure 4. MS/MS spectra the selected $[\mathrm{M}+\mathrm{H}]^{+}$ions: (a) intermediate 6aa, 7aa or $8 \mathbf{a a}$ (collision energy at $20 \mathrm{eV}$ ); (b) intermediate $6 \mathbf{a b}$, $7 \mathbf{a b}$ of $8 \mathbf{a b}$ (collision energy at $20 \mathrm{eV}$ ); (c) intermediate $6 \mathbf{b b}, 7 \mathbf{b b}$ or $8 \mathbf{b b}$ (collision energy at $25 \mathrm{eV}$ ). between 9aa $\cdot \mathrm{H}^{+}(\mathrm{m} / \mathrm{z} 602)$ and $\mathbf{1} \cdot \mathrm{H}^{+}(\mathrm{m} / \mathrm{z} 324)$ is shown in the insert in Figure 1.

For further structural characterization of the catalyst and intermediates, tandem mass spectrometric analysis was utilized. As shown in Scheme 3, the proton is located at the $\mathrm{N}$ atom of the primary or tertiary amine, since the fragment ion at $\mathrm{m} / \mathrm{z} 307$ from the protonated catalyst must have two isomeric structures, which produce the fragment ions at $\mathrm{m} / \mathrm{z} 264$ and 198, respectively. The result implies that a pentacycle could be formed through $\mathrm{N}-\mathrm{H}-\mathrm{N}$ hydrogen bonding, which possibly influences the conformation of catalyst and further influences the reactive enantioselectivity. The MS/MS spectrum of protonated intermediate $3 \mathbf{a}$ is very similar to catalyst 1 (Figure 2) and the fact that no fragment ion at $\mathrm{m} / \mathrm{z} 324[\mathbf{1}+\mathbf{H}]^{+}$was observed indicates that cleavage is difficult on the iminium double-bond (Scheme 4a). The fragment ion at $\mathrm{m} / \mathrm{z} 154$ was possibly generated by the loss of a HCN molecule from the intermediate $5 \mathbf{a}$ (Figure 2). In the MS/MS spectrum of $m / z 668$ (Figure 4), the fragment ion at $m / z 486[3 \mathbf{a}+\mathrm{H}]^{+}$

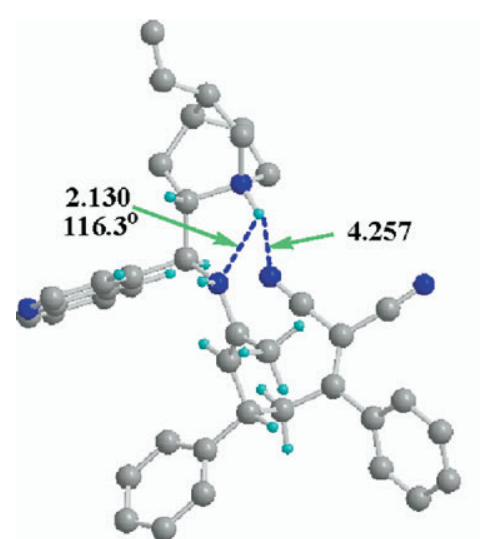

6bb-enamine ( 7.34 )

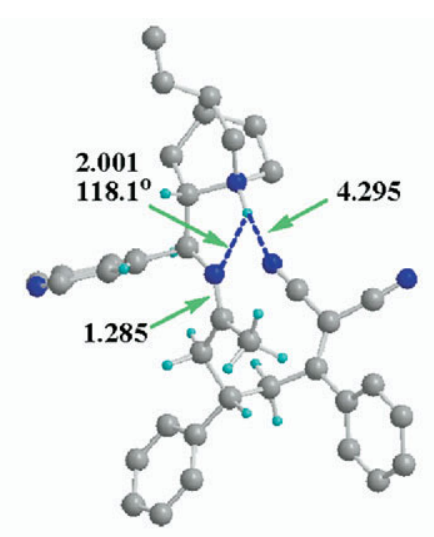

6/7bb-imine ( 0.00$)$

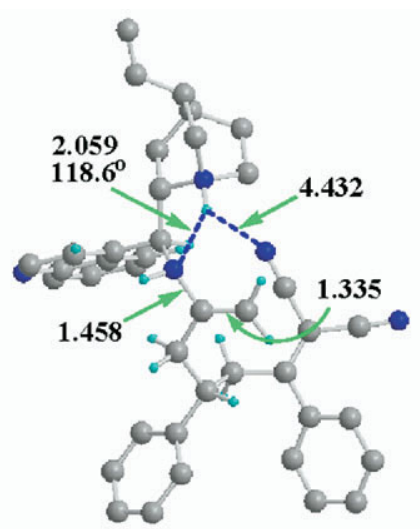

7bb-enamine ( 16.36 )

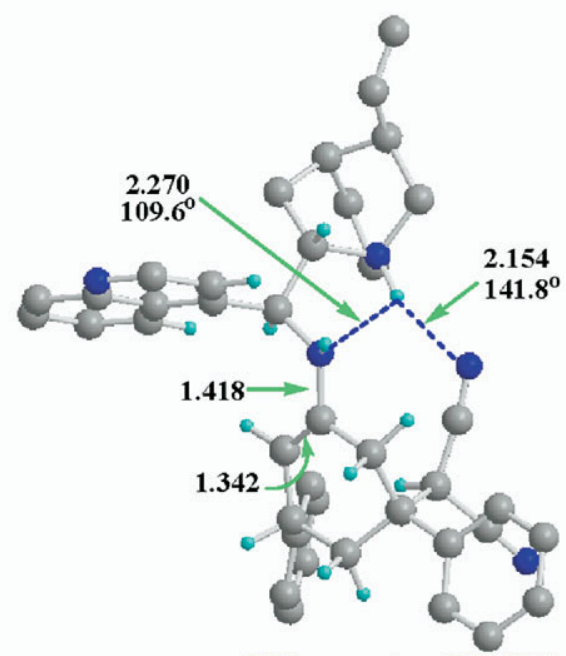

8bb-enamine (13.25)

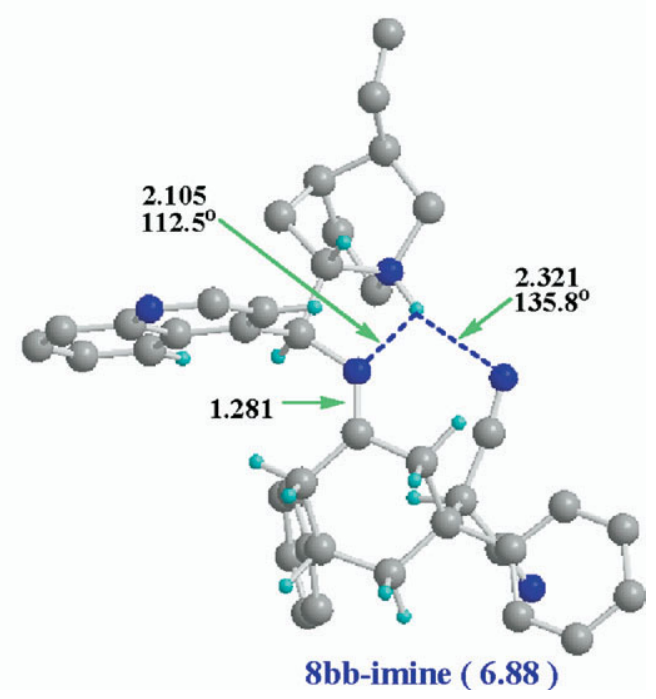

Figure 5. Calculated structures and relative free energies $(\mathrm{kcal} / \mathrm{mol})$ of isomeric intermediates by the B3LYP/6-31G(d) method, the parameters of distance shown in angstrom and angle in degree. Most hydrogen atoms were omitted for clarity. 


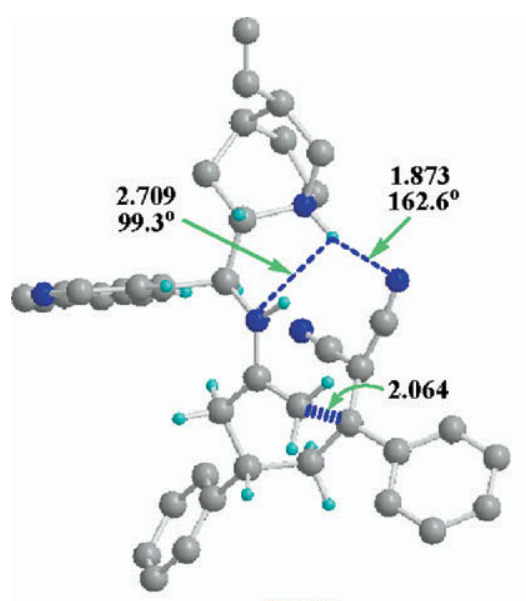

TS-78

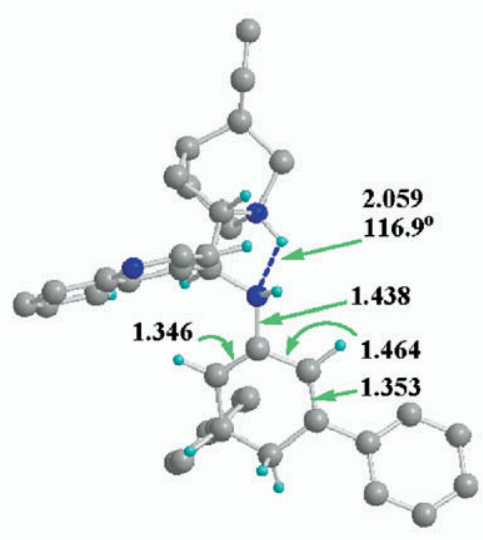

9bb-enamine

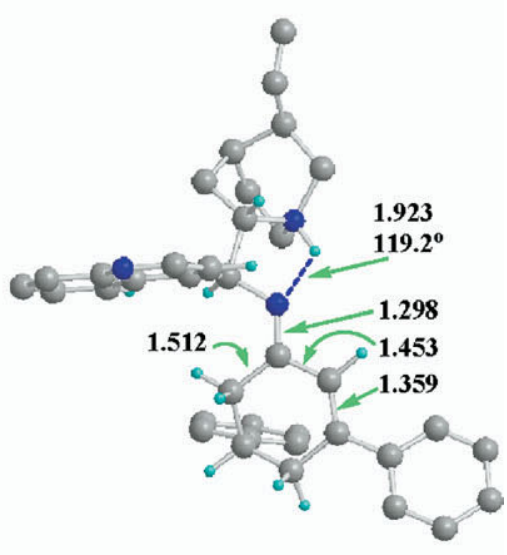

9bb-imine

Figure 6. Calculated structures of transition state and isomeric intermediates of $\mathbf{9 b b}$ by the B3LYP/6-31G(d) method. The parameters of distance are shown in angstrom. Most hydrogen atoms were omitted for clarity.

can be formed by retro-Michael addition reaction from the protonated intermediate 6aa [12]; the fragment ion at $m / z 602[10 \mathrm{aa}+\mathrm{H}]^{+}$can be formed by the loss of a $\mathrm{H}_{2} \mathrm{C}(\mathrm{CN})_{2}$ molecule from the protonated intermediate 8aa; [the fragment ion at $m / z 602[10 \mathbf{a a}+\mathrm{H}]^{+}$can also be produced from the protonated intermediates $6 \mathbf{a a}$ and 7aa through forming intermediate 8aa. However, the loss of a $\mathrm{H}_{2} \mathrm{C}(\mathrm{CN})_{2}$ molecule is difficult to occur in intermediates 6aa and 7aa;] the fragment ion at $\mathrm{m} / \mathrm{z} 324$ $[\mathbf{1}+\mathrm{H}]^{+}$possibly results from protonated intermediate 6aa, 7aa, or 8aa indicating that intermediate 6aa, 7aa, or 8aa may have an enamine structure, since cleavage is difficult on an iminium double-bond. The different fragmentation patterns between enamine and iminium structures and among intermediates 6aa, 7aa, and 8aa are shown in detail in Scheme 4 . In the MS/MS spectrum of protonated intermediate 9aa, the observation of the fragment ion at $m / z 324[\mathbf{1}+\mathbf{H}]^{+}$indicates the presence of enamine structure. Isotope analysis was carried out when the intermediates contain a chlorine atom. The other two reaction systems studied give similar results except that there is no observation of the fragment ion at $m / z 324[\mathbf{1}+\mathbf{H}]^{+}$in the MS/MS spectrum of $[9 \mathbf{b b}+\mathrm{H}]^{+}$.

To investigate the reaction mechanisms more in detail, ab initio quantum mechanical calculations was focused on the intermediates $6 \mathbf{b b}, 7 \mathbf{b b}, \mathbf{8 b b}$, and the transition-state from $\mathbf{7 b b}$ to $\mathbf{8 b b}$, and subsequent product $\mathbf{9 b b}$. The most possible low-energy minimum structures located for these isomeric intermediates, which all were stabilized by favorable polar interacting between the positive charged tertiary iminium and electronic density-rich cyano moiety are shown in Figure 5. The transition-state of the cyclization from $7 \mathbf{b b}$ to $8 \mathbf{b b}$ (Figure 6, TS-78) was investigated and the corresponding activation free-energy was predicted to be $\sim 17.79$ $\mathrm{kcal} / \mathrm{mol}$. The reaction barrier of the conversion from $\mathbf{7 b b}$ to $\mathbf{8 b b}$ is near to the difference of stability thermo- dynamically between $7 \mathrm{bb}$-enamine and $6 / 7 \mathrm{bb}$-imine. This indicated that the transformation from $7 \mathbf{b b}$ to $\mathbf{8 b b}$ could take place under the reaction situations of isomerization between $7 \mathrm{bb}$-enamine and $6 / 7 \mathrm{bb}$ imine. However, it seems that the reaction should prefer to the formation of $7 \mathbf{b b}$ instead of $\mathbf{8 b b}$, since the $6 / 7 \mathbf{b b}$-imine is thermodynamically more stable than $8 \mathrm{bb}$-imine by $\sim 7 \mathrm{kcal} / \mathrm{mol}$. To insight the driving forces of this reaction, the further study on the elimination of $\mathrm{CH}_{2}(\mathrm{CN})_{2}$ from $8 \mathbf{b b}$ to give $9 \mathbf{b b}$ and dicyanomethane was carried out and the located structures $\mathbf{9 b b}$-enamine and $\mathbf{9 b b}$-imine are shown in Figure 6. The formation of $\mathbf{9 b b}$-imine and dicyanomethane was predicted to be thermodynamically more favorable than 6/7bb-imine by $\sim 10 \mathrm{kcal} / \mathrm{mol}$. Thus, these calculations indicated that the isomerization and conversion among these isomeric intermediates are reasonable and preferable entropy arising from the elimination of $\mathrm{CH}_{2}(\mathrm{CN})_{2}$ from $\mathbf{8 b b}$-imine broke the various equilibria and drew the reaction sequence towards the final products in this studied reaction system.

In addition, the reaction system of catalyst $\mathbf{1}, \mathbf{2 b}$, $\alpha, \alpha$-dicyanoolefin 11, and TFA in THF (Scheme 5) was studied under the same conditions. The absolute abundance of deprotonated $\alpha, x$-dicyanoolefin $\mathbf{1 1}$ is obviously lower than that of the deprotonated compound $4 \mathbf{a}$ or $4 \mathrm{~b}$ under the same injection conditions (Figure 3 ),<smiles>N#CC(C#N)=C1CCSc2ccccc21</smiles>

11

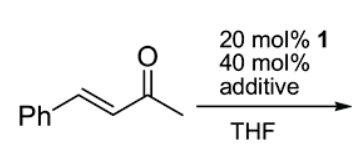

2b

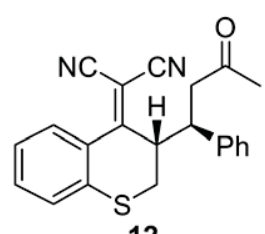

12
Scheme 5. Michael addition reaction of $\alpha, \beta$-unsaturated ketone and $\alpha, \alpha$-dicyano-olefin catalyzed by 9 -amino-9-deoxyepiquinine. 
which indicates that deprotonated $\alpha$, $\alpha$-dicyanoolefin 11 is more active and that intermediates similar to 6 or 7 cannot be observed, which supports that intramolecular Michael addition cannot occur in compound $\mathbf{1 2}$.

\section{Conclusion}

The proposed major intermediates for the catalytic cycle of Michael-Michael-retro Michael addition reactions of $\alpha, \alpha$-dicyanoolefins and $\alpha, \beta$-unsaturated ketones catalyzed by 9 -amino-9-deoxyepiquinine were successfully intercepted and structurally characterized using ESIMS, ESI-MS/MS, and ab initio quantum mechanical calculations. Some isomeric intermediates, including isomeric enamine and imine structures, were differentiated. Structural characteristics of protonated catalyst and the relationship between ion activity and absolute abundance are of interest. Further studies in this field are now being carried out in our laboratory.

\section{References}

1. Tian, S. K.; Chen, Y.; Hang, J.; Tang, L.; Madaid, P.; Deng, L. Asymmetric Organic Catalysis with Modified Cinchona Alkaloids. Acc. Chem. Res. 2004, 37, 621-631.

2. (a) Dijkstra, G. D. H.; Kellogg, R. M.; Wynberg, H.; Svendsen, J. S.; Marko, I. Sharpless, K. B. Conformational Study of Cinchona Alkaloids. A Combined NMR, Molecular Mechanics, and X-ray Approach. J. Am. Chem. Soc. 1989, 111, 8069. (b) Olsen, R. A.; Borchardt, D.; Mink, L.; Agarwal, A.; Mueller, L. J.; Zaera, F. Effect of Protonation on the Conformation of Cinchonidine. J. Am. Chem. Soc. 2006, 128, 1559415595 .

3. (a) Whitehouse, C. M.; Dreyer, R. N.; Yamashita, M.; Fenn, J. B. Electrospray Interface for Liquid Chromatographs and Mass Spectrometers. Anal. Chem. 1985, 57, 675-679. (b) Fenn, J. B.; Mann, M.; Meng, C. K.; Wong, S. F.; Whitehouse, C. M. Electrospray Ionization for Mass Spectrometry of Large Biomolecules. Science 1989, 246, 64-71. (c) Cole, R. B. Electrospray Ionization Mass Spectroscopy: Fundamentals, Instrumentation, and Applications; Wiley: New York, 1997

4. De la Mora, J. F.; Van Berkel, G. J.; Enke, C. G.; Cole, R. B.; MartinezSanchez, M.; Fenn, J. B. Electrochemical Processes in Electrospray Ionization Mass Spectrometry. J. Mass Spectron. 2000, 35, 939-952.

5. (a) Meyer, S.; Metzger, J. O. Use of Electrospray Ionization Mass Spectrometry for the Investigation of Radical Cation Chain Reactions in Solution: Detection of Transient Radical Cation. Anal. Bioanal. Chem. 2003, 377, 1108-1114. (b) Meyer, S.; Koch, R.; Metzger, J. O. Investigation of Reactive Intermediates of Chemical Reactions in Solution by Electrospray Ionization Mass Spectrometry: Radical Cation Chain Reactions. Angew. Chem. Int. Ed. 2003, 42, 4700-4703. (c) Furmeier, S.; Metzger, J. O. Detection of Transient Radical Cations in Electron Transfer-Initiated Diels-Alder Reactions by Electrospray Ionization Mass Spectrometry. J. Am. Chem. Soc. 2004, 126, 14485-14492. (d) GriepRaming, J.; Meyer, S.; Bruhn T.; Metzger, J. O. Investigation of Reactive Intermediates of Chemical Reactions in Solution by Electrospray Ionization Mass Spectrometry: Radical Chain Reactions. Angew. Chem. Int. Ed. 2002, 41, 2738-2742. (e) Santos, L. S.; Metzger, J. O. Study of Homogeneously Catalyzed Ziegler-Natta Polymerization of Ethene by ESI-MS. Angew. Chem. Int. Ed. 2006, 45, 977-981. (f) Marqez, C., Metzger, J. O. ESI-MS Study on Aldol Reaction Catalyzed by L-proline. Chem. Commun. 2006, 14, 1539-1541.
6. (a) Zhang, X.; Liao, Y.; Qian, R.; Wang, H.; Guo Y. L. Investigation of Radical Cation in Electrophilic Fluorination by ESI-MS. Org. Lett. 2005, 7, 3877-3880. (b) Qian, R.; Guo, H.; Liao, Y.; Guo, Y. L.; Ma, S. M. Probing the Mechanism of the Palladium-Catalyzed Addition of Organoboronic Acids to Allenes in the Presence of AcOH by ESI-FTMS. Angew. Chem. Int. Ed. 2005, 44, 4771-4774. (c) Guo, H.; Qian, R.; Liao, Y.; Ma, S. M.; Guo, Y. L. ESI-MS Studies on the Mechanism of Pd(0)catalyzed Three-Component Tandem Double Addition-Cyclization Reaction. J. Am. Chem. Soc. 2005, 127, 13060-13064. (d) Zhang, X.; Guo, Y. L. Electrospray Ionization Mass Spectrometric Study on the afluorination of Aldehydes. Rapid Commun. Mass Spectrom. 2006, 20, 3477.

7. (a) Ferraz, H. M. C.; Prechtl, F. L. C.; Goncalo, E. R. S.; Santos, L. S.; Eberlin, M. N. Unexpected Synthesis of Conformationally Restricted Analogues of $\gamma$-Amino Butyric Acid (GABA): Mechanism Elucidation by Electrospray Ionization Mass Spectrometry. J. Org. Chem. 2005, 70, 110-114. (b) Raminelli, C.; Prechtl, M. H. G.; Santos, L. S.; Eberlin, M. N.; Comasseto, J. V. Coupling of Vinylic Tellurides with Alkynes Catalyzed by Palladium Dichloride: Evaluation of Synthetic and Mechanistic Details. Organometal LICS 2004, 23, 3990-3996. (c) Sabino, A. A. Machado, A. H. L.; Correia, C. R. D.; Eberlin, M. N. Probing the Mechanism of the Heck Reaction with Arene Diazonium Salts by Electrospray Mass and Tandem Mass Spectrometry. Angew. Chem. Int. Ed. 2004, 43, 2514-2518. (d) Santos, L. S. Pavam, C. H. Almeida, W. P. Coelho, F.; Eberlin, M. N. Probing the Mechanism of the Baylis-Hillman Reaction by Electrospray Ionization Mass and Tandem Mass Spectrometry. Angew. Chem. Int. Ed. 2004, 43, 4330-4333.

8. Xie, J. W.; Chen, W.; Li, R.; Zeng, M.; Du, W.; Yue, L.; Chen, Y. C.; Wu, Y.; Zhu, J.; Deng, J. G. Highly Asymmetric Michael Addition to $\alpha, \beta$-Unsaturated Ketones Catalyzed by 9-Amino-9-deoxyepiquinine. Angew. Chem. Int. Ed. 2007, 46, 389-392.

9. (a) Becke, A. D. J. Chem. Phys. A New Mixing of Hartree-Fock and Local Density-Functional Theories. 1993, 98, 1372-1377. (b) Lee. C.; Yang, W.; Parr, R. G. Developemnt of the Colle-Salvetti Correlation-Energy Formula Into a Functional of the Electron Density. Phys. Rev. B 1988, 37, 785-789.

10. (a) Ditchfield, R.; Hehre, W. J.; Pople, J. A.; Self-Consistent MolecularOrbital Methods. IX. An Extended Gaussian-Type Basis for MolecularOrbital Studies of Organic Molecules. J. Chem. Phys. 1972, 56, 2257-2261. (b) Heher, W. J.; Ditchfield, R.; Pople, J. A. Self-Consistent MolecularOrbital Methods. XII. Further Extensions of Gaussian-Type Basis Sets for Use in Molecular Orbital Studies of Organic Molecules. J. Chem. Phys. 1972, 56, 2257-2261. (c) Hariharan, P. C.; Pople, J. A. Influence of Polarization Functions on MO Hydrogenation Energies. Theor. Chim. Acta 1973, 28, 213-222.

11. Gaussian 03, Revision C.02, Frisch, M. J.; Trucks, G. W.; Schlegel, H. B.; Scuseria, G. E.; Robb, M. A.; Cheesmena, J. R.; Montgomery, Jr., J. A.; Vreven, T.; Kudin, K. N.; Burant, J. C.; Millam, J. M.; Iyengar, S. S.; Tomasi, J.; Barone, V.; Mennucci, B.; Cossi, M.; Scalmani, G.; Rega, N.; Ptersson, G. A.; Nakatsuji, H. Hada, M.; Ehara, M.; Toyota, K.; Fukuda, R.; Hasegawa, J.; Ishida, M.; Nakajima, T.; Honda, Y.; Kitao, O.; Nakai, H.; Klene, M.; Li, X.; Knox, J. E.; Hratchian, H. P.; Cross, J. B.; Bakken, V.; Adamo, C.; Jaramillo, J.; Gomperts, R.; Stratman, R. W.; Yazyev, O.; Austin, A. J.; Cammi, R.; Pomelli, C.; Ochterski, J. W.; Ayala, P. Y.; Morokuma, K.; Voth, G. A.; Salvador, P.; Dannenberg, J. J.; Zakrzewski, V. G.; Dapprich, S.; Daniels, A. D.; Stain, M. C.; Farkas, O.; Malick, D. K.; Rabukc, A. D.; Raghavachari, K.; Foresman, J. B.; Oritz, J. V.; Cui, Q.; Baboul, A. G.; Ckofford, S.; Cioslowski, J.; Stafanov, B. B.; Liu, G.; Liashenko, A.; Piskorz, P.; Komaromi, I.; Martin, R. L.; Fox, D. J.; Keith, T.; Al-Laham, M. A.; Peng, C. Y.; Nanayakkara, A.; Challacombe, M.; Gill, P. M. W.; Johnson, B.; Chen, W.; Wong, M. W.; Gonzalez, C.; and Pople, J. A.; Gaussian, Inc., Wallingford CT, 2004.

12. (a) Wang, H. Y.: Guo, Y. L.: Lu, L. Studies of Rearrangement reactions of Protonated and Lithium Cationized 2-Pyrimidinyloxy-Narylbenzylamine Derivatives by MALDI-FT-ICR Mass Spectrometry. J. Am. Soc. Mass Spectrom. 2004, 15, 1820-1832. (b) Wang, H. Y.; Zhang, X.; Guo, Y. L.; Lu, L. Mass Spectrometric Studies of the Gas Phase Retro-Michael Type Fragmentation Reactions of 2-Hydroxybenzyl-NPyrimidinylamine Derivatives. J. Am. Soc. Mass Spectrom. 2005, 16, 1561-1573. 